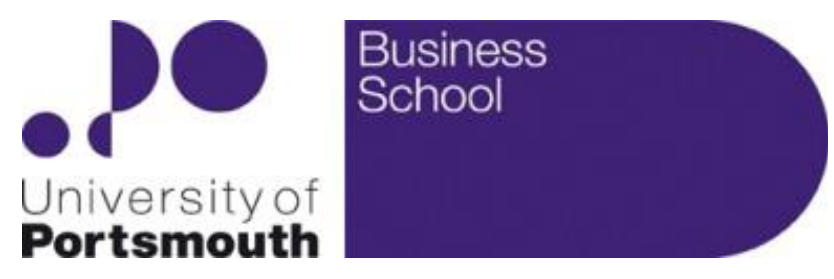

Working Papers in Economics \& Finance

2020-04

\title{
Dynamic Connectedness And Spillovers Across Sectors: Evidence From The Indian Stock Market
}

Ioannis Chatziantoniou, Portsmouth Business School

David Gabauer, Johannes Kepler University Hardik A. Marfatia, Northeastern Illinois University 


\title{
Dynamic Connectedness And Spillovers Across Sectors: Evidence From The Indian Stock Market
}

\author{
Ioannis Chatziantoniou $\rrbracket^{\llbracket}$ David Gabauer ${ }^{\dagger, \ddagger}$, and Hardik A. Marfatia ${ }^{\S, *}$ \\ IEconomics and Finance Subject Group, University of Portsmouth, Portsmouth Business School, Portland Street, Portsmouth, \\ PO1 3DE, United Kingdom. \\ †Software Competence Center Hagenberg Softwarepark 21, 4232 Hagenberg, Austria. \\ ${ }^{\ddagger}$ Institute of Applied Statistics, Johannes Kepler University, Altenbergerstraße 69, 4040, Linz, Austria. \\ $\S$ Department of Economics, Northeastern Illinois University, $5500 \mathrm{~N}$ St Louis Avenue, BBH 344G, Chicago, IL 60625, United \\ States. \\ * Corresponding Author
}

\begin{abstract}
This paper explores stock market sectoral connectedness for the emerging market economy of India. We use the time-varying parameter vector autoregressive dynamic connectedness of Antonakakis and Gabauer (2017). Results show that the stock market sectoral connectedness varies across time. Connectedness is strongest among sectors during the 2008 crisis, the double-digit inflation and stock market crash of 2011, national elections of 2014, and the historic demonetization of 2016. In addition, consumers' spending, industry, finance, and basic materials appear to be net transmitters of shocks. By contrast, information technology, fast moving consumer goods, healthcare, and telecommunications are net receivers of shocks. This paper can help formulate policies aiming at alleviating sectoral imbalances and promoting balanced growth, and also benefit investors with devising optimal portfolio diversification strategies.
\end{abstract}

Keywords: Emerging Markets, Sectoral Spillover, Variance Decomposition, Dynamic Connectedness, Stock Market Returns, TVP-VAR.

JEL codes: C32, C50, G15. 


\section{Introduction}

Insights into connectedness and information spillovers across sectors can guide policy design, macroeconomic research, and portfolio management. This information on connectedness helps policymakers identify sectors that are leading/lagging in growth. It also enables the efficient management of financial portfolios across sectors. This is particularly relevant for emerging market economies. In this paper, we estimate the dynamic connectedness across different sectors of the Indian stock market. This paper is first in the literature to explore connectedness at both the inter- and intra-sector level in the emerging market economy of India.

Existing studies largely focus on connectedness between international assets and stock markets. See, for example, Antonakakis et al. (2013, 2017); Ahmad et al. (2018); Shahzad et al. (2018); Lee and Lee (2019); Chow (2017) and Subramaniam et al. (2018); among others. One limitation of existing studies is that they only focus on general overall trends between stock markets or asset classes. While this provides an overall indicative trend of connectedness, it does not give insights into the dynamics of the different sectors of an economy. This is an important consideration because each sector is uniquely connected to the economy. Considering the financial sector, this sector plays a key role in the transmission of monetary policy shocks to the macroeconomy. One expects that shocks get transmitted from financial sectors to other sectors more so than the other way round. Also, since financial markets evolve continuously, its connection with other sector will accordingly change over time.

This in turn motivates two relevant questions. First, what is the nature of connectedness across different sectors, and how has it changed over time? Answering this question will offer insights into time-varying connections between all the sectors of economy. Second, what is the nature of connectedness at the inter-sectoral level across time? This will identify the leading and lagging sectors of the economy, thus helping policymakers and financial investors.

For an emerging market economy like India, exploring these questions is even more im- 
portant, particularly in light of some recent developments. First, the current administration had a landslide victory in the 2014 and 2019 national elections. One driver of this was the pro-growth policies like "Make in India" policy or financial inclusion polices like "Jan Dhan Yojana". These are expected to particularly promote sectors like manufacturing, small-scale industries, consumer durables, and banking sector. Nonetheless, there are frequent debates on the benefits of these policies in popular media and the literature (Mohan, 2014; Anand et al., 2015; Sangwan, 2015; Zhu et al., 2018). Second, despite the pro-growth policies, the economic growth of India has been sluggish in recent years. ${ }^{1}$ Third, the banking and financial channel in India is one of the key monetary policy transmission channels. Getting insights into the longrun efficacy of this channel attracts attention. Especially given the largest monetary policy experiment in the modern history of demonetizing 500 and 1,000 local currency notes. ${ }^{2}$

In this paper, we estimate the dynamic connectedness and information spillover across different sectors of the economy. The sectoral performance is measured by the daily returns of sectoral indices of the Bombay stock exchange (BSE). Using sectoral indices has several merits. It provides granular sector-level, high-frequency, up-to-date, and forward-looking information about the performance of different sectors of the Indian economy. Furthermore, we employ the time-varying parameter vector autoregressive (TVP-VAR) based connectedness approach in the spirit of Antonakakis and Gabauer (2017) which predicates upon the seminal work of Diebold and Yılmaz $(2012,2014)$. The adopted method can be considered an improvement of the standard rolling-windows approach which is typically associated with the arbitrary selection of the window-length and the inclusion of outliers.

Evidence suggests that the connectedness across sectoral returns has widely varied over

\footnotetext{
${ }^{1}$ The Reserve Bank of India in its annual report 2018-2019, revised real GDP growth forecast downward by 50 basis point to 6.9 percent for 2019-2020.

${ }^{2}$ On November 8, 2016, the government demonetized nearly $86 \%$ of the total currency note circulation. However, 99.3 percent of demonetized notes were returned to the banking system. This has spurred a debate on the efficacy of the policy action (Rani, 2016; Shirley, 2017; Dash, 2017; Chandrasekhar and Ghosh, 2018; Mohan and Ray, 2019; Chodorow-Reich et al., 2020).
} 
time. We find the strongest connection during the recent global financial crisis period. The landslide victory of the current ruling party in the 2014 elections and the historic 2016 demonetization of major currency notes also led to stronger linkages between sectoral performance. The main findings of the study suggest that different sectors play the role of net transmitters and net receivers of shocks. More specifically, consumer discretionary goods \& services, industry, finance, and basic materials are the net transmitters of shocks. By contrast, information technology, fast moving consumer goods, health care, and telecommunications are net receivers of shocks. The energy sector is both a transmitter and a receiver depending on the period under consideration. On a final note, findings show that the cyclical sectors are net transmitters, whereas non-cyclical sectors are net receivers of information.

This paper contributes to the literature in several ways. First, this is the first study to provide insights into connectedness across different sectors of an emerging economy, such as India. Second, in contrast with existing studies, this study investigates high-frequency sectorlevel forward-looking connections between sectors. This increases precision, while at the same time provides a holistic view of sectoral connectedness. These findings might inform sectordriven policy design as it helps identify the key sectors that lead other sectors. Third, this study employs a TVP-VAR approach, resulting in more precise and unbiased estimates.

\section{Data}

We measure sectoral performance by the sectoral indices returns of the Bombay stock exchange. Using this data is superior for several reasons. Sectoral indices capture the granular level performance of different sectors of the economy. This information is not available in other sources. Our approach is also superior because stock market prices are forward-oriented and updated daily. ${ }^{3}$ This improves precision and yet gives a holistic view of the connections across different

\footnotetext{
${ }^{3}$ Basic asset pricing theory suggests that stock market 'prices in' all the information that investors have at every point in time. This makes the stock prices forward-oriented and up-to-date.
} 
sectors. We use daily returns of S\&P BSE sectoral indices - as the raw series are unit root processes according to the Elliott et al. (1996) unit-root test - for all ten sectors for the period January 2007 to June 2019 sourced from BSE (Figure 1). The ten sectors are: Consumer Discretionary Goods \& Services (consumer discretionary), Energy (energy), Finance (finance), Fast-Moving Consumer Goods (FMCG), Health care (healthcare), Industry (industry), Information Technology (infotech), Basic Materials (materials), Telecommunications (telecom), and Utilities (utilities). The S\&P BSE sectoral indices are designed to provide a benchmark reflecting companies included in the S\&P BSE AllCap classified as members of a particular sector.

\section{[Insert Figure 1 around here]}

Table 1 presents a summary statistic of the sectoral performance. Finance, FMCG, and infotech provide the highest mean returns. In contrast, telecom and utilities provide the least returns on average. Conventional financial wisdom suggests that high (low) returns are likely associated with high (low) risks. However, this is not the case with some sectors. Both telecom and utilities, for example, have the lowest mean returns, but the risk measured by standard deviation is among the highest across all the sectors. We find that besides finance, industry and telecom sectors, all series are significantly negatively skewed. Furthermore, all variables are significantly leptokurtic and non-normally distributed. Additionally, we find that all series are autocorrelated and exhibit ARCH errors according to the weighted Portmanteau statistics.

\section{[Insert Table 1 around here]}

We also estimate correlation to get an overview of the relationship between sectors. The correlation matrix shows that the returns across all sectors move in tandem. We find some of the highest correlation between consumer discretionary goods \& services, finance, industry, basic material, and utilities. The infotech sector, though positively related to other sectors, has one of the weakest relationships in the group. One intuitive explanation could be that 
investors perception of this sector often leads to the out-performance of the sector relative to other sectors. This is not just the case with India, but even advanced markets like the U.S. The wide differences in the correlation from 0.41 to 0.88 further motivates us to explore the dynamic connections and how the shocks spillover between sectors.

\section{Methodology}

A widely used approach to trace and evaluate spillovers in a predetermined network is the connectedness approach proposed by Diebold and Yllmaz (2009, 2012, 2014). In the seminal papers the dynamics are estimated via a rolling-window VAR approach which faces some drawbacks such as (i) outliers sensitivity, (ii) arbitrarily chosen rolling-window sizes, (iii) loss of observations and (iv) the inability to analyze low-frequency datasets. Employing a TVP-VAR based connectedness framework - which is used in this study - overcomes those shortcomings as it is intensively discussed in Antonakakis and Gabauer (2017). Hence, this study applies the same methodology as in Antonakakis et al. (2018) and Gabauer and Gupta (2018). In particular, we are estimating the following TVP-VAR(1) model as suggested by the Bayesian information criterion (BIC) which can be outlined as follows,

$$
\begin{array}{rlrl}
\boldsymbol{z}_{t} & =\boldsymbol{B}_{t} \boldsymbol{z}_{t-1}+\boldsymbol{u}_{t} & \boldsymbol{u}_{t} & \sim N\left(\mathbf{0}, \boldsymbol{S}_{t}\right) \\
\operatorname{vec}\left(\boldsymbol{B}_{t}\right) & =\operatorname{vec}\left(\boldsymbol{B}_{t-1}\right)+\boldsymbol{v}_{t} & \boldsymbol{v}_{t} \sim N\left(\mathbf{0}, \boldsymbol{R}_{t}\right)
\end{array}
$$

where $\boldsymbol{z}_{t}, \boldsymbol{z}_{t-1}$ and $\boldsymbol{u}_{t}$ are $k \times 1$ dimensional vector and $\boldsymbol{B}_{t}$ and $\boldsymbol{S}_{t}$ are $k \times k$ dimensional matrices. $\operatorname{vec}\left(\boldsymbol{B}_{t}\right)$ and $\boldsymbol{v}_{t}$ are $k^{2} \times 1$ dimensional vectors whereas $\boldsymbol{R}_{t}$ is a $k^{2} \times k^{2}$ dimensional matrix.

In a further step, we are calculating the $H$-step ahead (scaled) generalized forecast error variance decomposition (GFEVD) introduced by Koop et al. (1996) and Pesaran and Shin (1998). Notably, the GFEVD is completely invariant of the variable ordering opposed to the 
orthorgonalized forecast error variance decomposition (see, Diebold and Yılmaz, 2009) ${ }^{4}$. We have decided to apply the GFEVD approach as - to the best of our knowledge - no economic theory is developed that determines the structure of sectoral shocks. Hence, choosing an arbitrary error structure will lead to unreasonable results and thus a GFEVD framework should be preferred (Wiesen et al., 2018). Since this concept requires to transform the TVP-VAR into a TVP-VMA model we make use of the Wold representation theorem: $\boldsymbol{z}_{t}=\sum_{i=1}^{p} \boldsymbol{B}_{i t} \boldsymbol{z}_{t-i}+\boldsymbol{u}_{t}=\sum_{j=0}^{\infty} \boldsymbol{A}_{j t} \boldsymbol{u}_{t-j}$.

The (scaled) GFEVD $\left(\phi_{i j, t}^{g} \tilde{(}(H)\right)$ normalizes the (unscaled) GFEVD $\left(\phi_{i j, t}^{g}(H)\right)$ in order that each row sums up to unity. $\tilde{\phi}_{i j, t}^{g}(H)$ represents the influence variable $j$ has on variable $i$ in terms of its forecast error variance share which is defined as the pairwise directional connectedness from $j$ to $i$. This indicator is computed by,

$$
\phi_{i j, t}^{g}(H)=\frac{S_{i i, t}^{-1} \sum_{t=1}^{H-1}\left(\boldsymbol{\iota}_{i}^{\prime} \boldsymbol{A}_{t} \boldsymbol{S}_{t} \iota_{j}\right)^{2}}{\sum_{j=1}^{k} \sum_{t=1}^{H-1}\left(\boldsymbol{\iota}_{i} \boldsymbol{A}_{t} \boldsymbol{S}_{t} \boldsymbol{A}_{t}^{\prime} \iota_{i}\right)} \quad \tilde{\phi}_{i j, t}^{g}(H)=\frac{\phi_{i j, t}^{g}(H)}{\sum_{j=1}^{k} \phi_{i j, t}^{g}(H)}
$$

with $\sum_{j=1}^{k} \tilde{\phi}_{i j, t}^{g}(H)=1, \sum_{i, j=1}^{k} \tilde{\phi}_{i j, t}^{g}(H)=k$, and $\iota_{j}$ corresponds to a selection vector with unity on the $j$ th position and zero otherwise.

Based upon the GFEVD, Diebold and Yllmaz (2012, 2014) derived their connectedness

\footnotetext{
${ }^{4}$ We want to stress out that even though we are talking about the spillovers of shocks we are well aware that those interpretation differs from the macroeconomic literature, however, with this interpretation we are just following the interpretations Diebold and Yilmaz $(2009,2012,2014)$ to be in-line with the connectedness literature.
} 
measures which are mathematically formulated as follows:

$$
\begin{aligned}
T O_{j t} & =\sum_{i=1, i \neq j}^{k} \tilde{\phi}_{i j, t}^{g}(H) \\
F R O M_{j t} & =\sum_{j=1, i \neq j}^{k} \tilde{\phi}_{i j, t}^{g}(H) \\
N E T_{j t} & =T O_{j t}-F R O M_{j t} \\
T C I_{t} & =k^{-1} \sum_{j=1}^{k} T O_{j t} \equiv k^{-1} \sum_{j=1}^{k} F R O M_{j t} . \\
N P D C_{j i, t} & =\tilde{\phi}_{j i, t}(H)-\tilde{\phi}_{i j, t}(H)
\end{aligned}
$$

As mentioned previously $\tilde{\phi}_{i j, t}^{g}(H)$ illustrates the impact a shock in variable $j$ has on variable $i$. Hence, Equation (3) represents the aggregated impact a shock in variable $j$ has on all other variables which is defined as the total directional connectedness to others whereas Equation (4) illustrates the aggregated influence all other variables have on variable $j$ that is defined as the total directional connectedness from others.

Equation (5): Subtracting the impact variable $j$ has on others by the influence others have on variable $j$ results in the net total directional connectedness which provides us with information whether a variable is a net transmitter or a net receiver of shocks. Variable $j$ is a net transmitter (receiver) of shocks - and hence driving (driven by) the network - when the impact variable $j$ has on others is larger (smaller) than the influence all others have on variable $j$, $N E T_{j t}>0\left(N E T_{j t}<0\right)$. Another essential measure is given by Equation (6) which represents the total connectedness index $\left(T C I_{t}\right)$ that is the average impact one variable has on all others. If this measure is relatively high it implies that the interconnectedness of the network and hence the market risk is high and vice versa. Since all aforementioned measures offer information on an aggregated basis, Equation (7) tells us more about the bilateral relationship between variable $j$ and $i$. The so-called net pairwise directional connectedness $\left(N P D C_{i j, t}\right)$ exhibits whether 
variable $i$ is driving or driben by variable $j$. Therefore, we subtract the impact variable $i$ has on variable $j$ from the influence variable $j$ has on variable $i$. If $N P D C_{j i, t}>0\left(N P D C_{j i, t}<0\right)$, it means that variable $j$ is dominating (dominated by) variable $i$.

\section{Empirical Results and Discussion}

This section presents the relevant findings pertaining to the recorded connectedness across the variables comprising our network. First, we present averaged results for total connectedness and discuss which sectors initially appear to act as net transmitters of shocks in the Indian economy and which ones as net receivers of shocks. In turn, we concentrate on dynamic results for total connectedness, in an effort to capture potential events reported during the full sample period that might have had a considerable impact on the role that each sector assumes over time. Finally, in order to identify bilateral interrelations across the sectors of our network, we also present pairwise connectedness results.

\subsection{Average Dynamic Connectedness}

We begin our analysis by considering the TCI. These results are reported in Table 2. Each row of Table 2 corresponds to the individual contribution of each sector to the forecast error variance of all other sectors of our network, while each column, to the forecast error variance that other sectors have contributed to each sector separately. It should also be noted that main diagonal elements represent own-variable effects while, off-diagonal elements, the effect from/to others. Both the three last rows and the last column of Table 2, provide an insightful summary of the results.

\section{[Insert Table 2 around here]}

In this regard, we note that innovations in this particular network have in fact considerable implications when it comes to forecast error variations. In particular, $74 \%$ of the forecast error 
variance can be attributed to cross-sectoral innovations within our network, which practically implies that own-variable effects account for less than 30\%. Given the high averaged TCI value, we deduce that there is indeed strong co-movement across the various sectors of economic activity in India. Prominent also among our results is that principal net transmitters of shocks (i.e., in average terms) are industry, consumer discretion goods \& services, and materials sectors. By contrast, principal net recipients of shocks throughout the sample period are the infotech, fast moving consumer goods, and telecom sectors.

\subsection{Dynamic Evolution of TCI}

In turn, we concentrate on the dynamic results of the study. The underlying logic for that is that average total connectedness serves primarily in order to summarise the relations of interest. In turn, this implies that average outcomes may actually mask a variety of events that took place during the sample period and resulted in considerable deviations from the average TCI value. For instance, utilizing an average approach may result in losing important information relating to specific developments in either the economic or the financial sphere of operations in India; that is, developments that might have induced a switch in the role assumed by some of the sectors included in our analysis.

This point becomes clearer, if we look at Figure 2. This Figure illustrates the evolution of the TCI value over time. Evidentially, total connectedness varies substantially over time, which is indicative of the fact that our network is quite sensitive to time-specific developments and events.

[Insert Figure 2 around here]

It is worth noting that connectedness oscillates around relatively high levels until 2012, when obviously there occurs some decoupling across sectors which results in lower TCI values. In turn, there is a new peak around 2014 before a new decoupling appears until late 2015. The 
same process subsequently repeats itself for a specific interval during year 2017. It follows that all the periods could comprise important information regarding the evolution of connectedness across the sectors of our network. Be it as it may though, we should explicitly note that even during these decoupling incidents, connectedness across our network remains at very high levels; that is, it is persistently recording TCI values higher than $60 \%$.

At this point it would also be instructive to investigate which sectors add to network interconnectedness and which are rather driven by it. We the relevant illustrate results in Figure 3.

\section{[Insert Figure 3 around here]}

In all panels of Figure 3, the black solid line represents the evolution of TCI over time. Furthermore, lines of different colours (both dotted and solid) correspond to the respective sectors under investigation. There are two ways to construct the connectedness index (i.e., either by considering shocks TO, or by considering shocks FROM) hence the use of both a solid and a dotted coloured line for each sector. In short, every time the line (i.e., dotted or solid) representing the sector exceeds the black solid TCI line, then, that sector has an important role in adding to the interconnectedness of the network. In other words, it is a sector that is highly interconnected with all other sectors. The reverse is also true. In this regard, according to the results of our study, sectors that are highly interconnected with other sectors and add considerably to the value of the TCI (over time) are: the consumers discretionary goods and services sector, industry and materials, utilities and finance. By contrast, sectors that do not add considerably to the interconnectedness of the system are: information technology, fastmoving consumer goods, telecommunications, as well as, health. The energy sector has a rather ambiguous effect although it clearly assumes a weaker role in adding to the TCI value in recent years. 


\subsection{Net Connectedness}

Considering forecast error variance effects, the chosen framework of analysis provides the opportunity to distinguish the various sectors of the Indian economy into net transmitting and net receiving economic sectors. To put differently, utilizing the relevant TVP connectedness measures we may produce a classification (on net terms) of the various economic sectors. In this regard, results can be presented in two layers. First, we can identify the role that each sector assumes throughout the period of analysis considering all other sectors simultaneously (i.e., net total connectedness). Second, we may also conduct bivariate analysis in order to highlight the extent of the relationship between specific pairs of sectors (i.e., net pairwise connectedness). It should be noted that given the dynamic character of the analysis, it is possible for one sector to assume both roles over time. The respective results are given by Figure 4 and Figures 5-7. In all Figures, positive values are associated with net transmitting and negative values with net receiving sectors of economic activity.

\section{[Insert Figure 4 around here]}

Starting with net total directional connectedness in Figure 4, we note that most sectors are quite persistent with regard to the role they apparently assume throughout the sample period. More specifically, industry, consumer discretionary goods \& services, materials, as well as, finance appear to be persistent transmitters of shocks in the Indian Economy. By contrast, sectors like infotech, fast moving consumer goods, as well as, telecom assume a rather persistent net receiving role. Finally, energy, utilities, and healthcare sectors do assume both roles over time; nonetheless, in all three cases it is rather evident that one of the two roles is rather dominating, considering this specific period of analysis.

We then turn to net pairwise connectedness. Results are given by Figure 5-7. We begin with the consumer discretionary goods \& services sector. More specifically this sector persistently 
transmits to all other sectors of the network, especially towards the end of the sample period. What is more, the impact of this sector appears to be more pronounced on energy, healthcare, infotech, fast moving consumer goods, and telecom sectors. By contrast, pairwise connectedness appears to be less pronounced when it comes to utilities, finance, industry and materials sectors. In connection with these last three sectors, the consumer discretionary goods \& services sector also assumes a net receiving role; nonetheless this is for a rather short period of time and of a rather negligible magnitude.

\section{[Insert Figure 5 around here]}

Turning to the sector of energy, we note that contrary to the consumer discretionary goods \& services sector, the role of the energy sector is not fixed to either that of a net receiver or that of a net transmitter. On one hand, energy receives from industry, utilities, materials, finance, and the consumer discretionary goods \& services sectors. On the other, it transmits rather persistently to infotech, and telecom sectors. In addition, its connectedness to healthcare is rather ambivalent; however, the magnitude of the link is rather low. On a final note, it is rather noteworthy that although energy is a persistent transmitter of shocks vis-à-vis the fast moving consumer goods sector for most of the period of analysis, it becomes a net recipient of shocks towards the end of the sample.

[Insert Figure 6 around here]

As far as the finance sector is concerned, it apparently transmits to most of the other sectors with the exception of industry. Apparently, the finance sector is more closely linked to infotech, fast moving consumer goods, telecom, and healthcare, and less closely linked to consumer discretionary goods \& services, materials, industry and utilities.

With regard to fast moving consumer goods, this sector is a net recipient vis-à-vis the consumer discretionary goods \& services sector, energy (although to reiterate an observation 
made above, the role is reversed towards the end of the sample), industry, materials, utilities and healthcare. It is less closely linked to infotech and telecom sectors.

\section{[Insert Figure 7 around here]}

With reference to other findings of the study, healthcare receives from industry, infotech, and utilities, while it assumes a rather ambivalent role regarding the telecom sector. The industry sector, on the other hand, is a persistent transmitter of shocks vis-à-vis infotech, telecom, and utilities sectors. Thought provokingly, the industry sector does not appear to transmit considerably to materials, which could perhaps be indicative of the strong interdependence of the two sectors.

Materials, appear to have a strong impact on telecom, acting as net transmitters of shocks. In particular, both information technology and telecom assume a net receiving role in relation to both utilities and materials.

Overall, the most important aspect perhaps, of the findings presented above is that in almost all of the cases, the various roles assumed by the sectors of interest are rather fixed throughout the sample period (even though they differ in magnitude), while in the very few cases where sectors apparently alternate over time between net transmitters and net receivers, the impact is rather not one of considerable magnitude.

\section{$5 \quad$ Implications for Policy Makers}

There are several key implications for policy makers that emerge from the evidence provided in this study. The first is to measure the effectiveness of economic policies. Evidence suggests that connectedness across sectors was high during the global financial crisis, overall reduced in the 2009-2014 period when the government policies were criticized to be passive and fluctuated in the post-2014 period when there was a pro-active role of fiscal policy. This implies that 
sectoral connectedness increases when there are extreme negative movements in the economy or when investors foresee pervasive effects of a policy change that benefits several sectors at the same time (which increases sectoral connectedness). In this sense, the results could serve as a yardstick for measuring policy effectiveness.

Second, the direction of pair-wise spillovers between sectors can guide policymakers in designing optimal policies for each sector. For example, the net connectedness of the financial sector is positive and significant to sectors like infotech, FMCG, telecom, and healthcare. It means that financial market reforms have positive spillover effects on these sectors. The analysis of historical developments also supports this finding. The central bank of the country (Reserve Bank of India) adopted flexible inflation targeting in February 2015. We note that immediately after that TCI was increased. At the same time, spillovers form the financial sector to other sectors also increased following this change. One plausible explanation is that investors perceived this to be a positive change for most sectors (leading to increased total connectedness) and increased spillover from finance to other sectors. Thus, by analyzing intra-sectoral connectedness, policymakers can design sector-driven policies more effectively. In retrospect, policy makers could consider the insights presented in this study in order to focus on the formulation of sector-specific policy reforms.

\section{Concluding Remarks}

Identifying the connection between different sectors of the economy is central to policy making and portfolio management. This is specifically important for an emerging market economy like India. In this paper, we use high-frequency Indian stock market sector returns data and estimate a time-varying parameter vector autoregression dynamic connectedness of Antonakakis and Gabauer (2017). Evidence suggests that the connection between sectoral performance varies considerably across time. We find the strongest connection around the recent financial crisis 
period. National level events such as the 2014 selections and 2016 demonetization also induced a strong connection between sectors. We find that shocks generally spillover from cyclical to non-cyclical sectors. More specifically, net transmitters of shocks are the consumer spending sector, industry, finance, and basic materials, whereas receivers include information technology, fast moving consumer goods, healthcare, and telecommunications.

\section{References}

Ahmad, W., Mishra, A. V., and Daly, K. J. (2018). Financial Connectedness Of BRICS And Global Sovereign Bond Markets. Emerging Markets Review, 37:1-16.

Anand, R., Kochhar, K., and Mishra, S. (2015). Make In India; Which Exports Can Drive The Next Wave Of Growth? Technical report, International Monetary Fund.

Anscombe, F. J. and Glynn, W. J. (1983). Distribution Of The Kurtosis Statistic B2 For Normal Samples. Biometrika, 70(1):227-234.

Antonakakis, N., Chatziantoniou, I., and Filis, G. (2013). Dynamic Co-Movements Of Stock Market Returns, Implied Volatility And Policy Uncertainty. Economics Letters, 120(1):8792.

Antonakakis, N., Chatziantoniou, I., and Filis, G. (2017). Oil Shocks And Stock Markets: Dynamic Connectedness Under The Prism Of Recent Geopolitical And Economic Unrest. International Review Of Financial Analysis, 50:1-26.

Antonakakis, N. and Gabauer, D. (2017). Refined Measures Of Dynamic Connectedness Based On TVP-VAR. Technical report, University Library of Munich, Germany.

Antonakakis, N., Gabauer, D., Gupta, R., and Plakandaras, V. (2018). Dynamic Connectedness Of Uncertainty Across Developed Economies: A Time-Varying Approach. Economics Letters, 166:63-75.

Chandrasekhar, C. and Ghosh, J. (2018). The Financialization Of Finance? Demonetization And The Dubious Push To Cashlessness In India. Development And Change, 49(2):420436.

Chodorow-Reich, G., Gopinath, G., Mishra, P., and Narayanan, A. (2020). Cash And The Economy: Evidence From India's Demonetization. Quarterly Journal Of Economics, 135(1):57103.

Chow, H. K. (2017). Volatility Spillovers And Linkages In Asian Stock Markets. Emerging Markets Finance And Trade, 53(12):2770-2781.

D'Agostino, R. B. (1970). Transformation To Normality Of The Null Distribution Of G1. Biometrika, 57(3):679-681.

Dash, A. (2017). A Study On Socio Economic Effect Of Demonetization In India. International Journal Of Management And Applied Science, 3(3):13-15.

Diebold, F. X. and Yllmaz, K. (2009). Measuring Financial Asset Return And Volatility Spillovers, With Application To Global Equity Markets. Economic Journal, 119(534):158171. 
Diebold, F. X. and Yılmaz, K. (2012). Better To Give Than To Receive: Predictive Directional Measurement Of Volatility Spillovers. International Journal Of Forecasting, 28(1):57-66.

Diebold, F. X. and Yllmaz, K. (2014). On The Network Topology Of Variance Decompositions: Measuring The Connectedness Of Financial Firms. Journal Of Econometrics, 182(1):119134 .

Elliott, G., Rothenberg, T. J., and Stock, J. H. (1996). Efficient Tests For An Autoregressive Unit Root. Econometrica, 64(4):813-836.

Fisher, T. J. and Gallagher, C. M. (2012). New Weighted Portmanteau Statistics For Time Series Goodness Of Fit Testing. Journal Of The American Statistical Association, 107(498):777-787.

Gabauer, D. and Gupta, R. (2018). On The Transmission Mechanism Of Country-Specific And International Economic Uncertainty Spillovers: Evidence From A TVP-VAR Connectedness Decomposition Approach. Economics Letters, 171:63-71.

Jarque, C. M. and Bera, A. K. (1980). Efficient Tests For Normality, Homoscedasticity And Serial Independence Of Regression Residuals. Economics Letters, 6(3):255-259.

Koop, G., Pesaran, M. H., and Potter, S. M. (1996). Impulse Response Analysis In Nonlinear Multivariate Models. Journal Of Econometrics, 74(1):119-147.

Lee, H. S. and Lee, W. S. (2019). Network Connectedness Among Northeast Asian Financial Markets. Emerging Markets Finance And Trade, pages 1-18.

Mohan, B. (2014). Pradhan Manti Jan Dhan Yojana (PMJDY): Features, Needs And Challenges. International Journal Of Marketing, Financial Services $\& 5$ Management Research, ISSN, pages 2277-3622.

Mohan, R. and Ray, P. (2019). Indian Monetary Policy In The Time Of Inflation Targeting And Demonetization. Asian Economic Policy Review, 14(1):67-92.

Pesaran, H. H. and Shin, Y. (1998). Generalized Impulse Response Analysis In Linear Multivariate Models. Economics Letters, 58(1):17-29.

Rani, G. (2016). Effects Of Demonetization On Retail Outlets. International Journal Of Applied Research, 2(12):400-401.

Sangwan, S. (2015). Making "Make In India" A Realism: Role Of FDI. International Journal Of Applied Research, 1(7):770-773.

Shahzad, S. J. H., Mensi, W., Hammoudeh, S., Rehman, M. U., and Al-Yahyaee, K. H. (2018). Extreme Dependence And Risk Spillovers Between Oil And Islamic Stock Markets. Emerging Markets Review, 34:42-63.

Shirley, M. A. J. (2017). Impact Of Demonetization In India. International Journal Of Trend In Research And Development, pages 20-23.

Subramaniam, S., Gabauer, D., and Gupta, R. (2018). On the transmission mechanism of asiapacific yield curve characteristics. Technical report, University of Pretoria, Department of Economics.

Wiesen, T. F., Beaumont, P. M., Norrbin, S. C., and Srivastava, A. (2018). Are Generalized Spillover Indices Overstating Connectedness? Economics Letters, 173:131-134.

Zhu, H., Gupta, A., Majumder, B., and Steinbach, S. (2018). Short-Term Effects Of India's Demonetization On The Rural Poor. Economics Letters, 170:117-121. 
Table 1: Summary Statistics

\begin{tabular}{|c|c|c|c|c|c|c|c|c|c|c|}
\hline & consdisc & energy & finance & fmcg & health & industry & infotech & materials & telecom & utilities \\
\hline Mean & 0.033 & 0.039 & 0.053 & 0.057 & 0.042 & 0.026 & 0.043 & 0.029 & -0.001 & 0.017 \\
\hline Variance & 1.867 & 2.88 & 3.002 & 1.568 & 1.375 & 2.733 & 2.585 & 2.942 & 3.61 & 2.666 \\
\hline Skewness & $\begin{array}{c}-0.645 * * * \\
(0.000)\end{array}$ & $\begin{array}{c}-0.301 * * * \\
(0.000)\end{array}$ & $\begin{array}{c}0.028 \\
(0.502)\end{array}$ & $\begin{array}{c}-0.222 * * * \\
(0.000)\end{array}$ & $\begin{array}{c}-0.570 * * * \\
(0.000)\end{array}$ & $\begin{array}{l}-0.062 \\
(0.144)\end{array}$ & $\begin{array}{c}-0.107 * * \\
(0.012)\end{array}$ & $\begin{array}{c}-0.374 * * * \\
(0.000)\end{array}$ & $\begin{array}{l}-0.021 \\
(0.625)\end{array}$ & $\begin{array}{c}-0.427 * * * \\
(0.000)\end{array}$ \\
\hline Kurtosis & $\begin{array}{c}7.593 * * * \\
(0.000)\end{array}$ & $\begin{array}{c}9.820 * * * \\
(0.000)\end{array}$ & $\begin{array}{c}7.013 * * * \\
(0.000)\end{array}$ & $\begin{array}{c}3.600 * * * \\
(0.000)\end{array}$ & $\begin{array}{c}4.881 * * * \\
(0.000)\end{array}$ & $\begin{array}{c}6.537 * * * \\
(0.000)\end{array}$ & $\begin{array}{c}5.322 * * * \\
(0.000)\end{array}$ & $\begin{array}{c}5.362 * * * \\
(0.000)\end{array}$ & $\begin{array}{c}4.348 * * * \\
(0.000)\end{array}$ & $\begin{array}{c}11.658 * * * \\
(0.000)\end{array}$ \\
\hline JB & $\begin{array}{c}8282.342 * * * \\
(0.000)\end{array}$ & $\begin{array}{c}13515.396 * * * \\
(0.000)\end{array}$ & $\begin{array}{c}6867.247 * * * \\
(0.000)\end{array}$ & $\begin{array}{c}1836.922 * * * \\
(0.000)\end{array}$ & $\begin{array}{c}3507.585 * * * \\
(0.000)\end{array}$ & $\begin{array}{c}5969.240 * * * \\
(0.000)\end{array}$ & $\begin{array}{c}3961.188 * * * \\
(0.000)\end{array}$ & $\begin{array}{c}4093.243 * * * \\
\quad(0.000)\end{array}$ & $\begin{array}{c}2640.023 * * * \\
(0.000)\end{array}$ & $\begin{array}{c}19077.694 * * * \\
(0.000)\end{array}$ \\
\hline ERS & $\begin{array}{c}-11.109 * * * \\
(0.000)\end{array}$ & $\begin{array}{c}-10.212 * * * \\
(0.000)\end{array}$ & $\begin{array}{c}-12.737 * * * \\
(0.000)\end{array}$ & $\begin{array}{c}-9.788 * * * \\
(0.000)\end{array}$ & $\begin{array}{c}-7.022 * * * \\
(0.000)\end{array}$ & $\begin{array}{c}-13.028 * * * \\
(0.000)\end{array}$ & $\begin{array}{c}-11.416 * * * \\
(0.000)\end{array}$ & $\begin{array}{c}-9.312 * * * \\
(0.000)\end{array}$ & $\begin{array}{c}-10.796 * * * \\
(0.000)\end{array}$ & $\begin{array}{c}-15.380 * * * \\
(0.000)\end{array}$ \\
\hline$Q(20)$ & $\begin{array}{c}144.743 * * * \\
(0.000)\end{array}$ & $\begin{array}{c}84.262 * * * \\
(0.000)\end{array}$ & $\begin{array}{c}118.330 * * * \\
(0.000)\end{array}$ & $\begin{array}{c}47.124 * * * \\
(0.001)\end{array}$ & $\begin{array}{c}103.783 * * * \\
(0.000)\end{array}$ & $\begin{array}{c}123.117 * * * \\
(0.000)\end{array}$ & $\begin{array}{c}50.593 * * * \\
(0.000)\end{array}$ & $\begin{array}{c}102.818 * * * \\
(0.000)\end{array}$ & $\begin{array}{c}62.425 * * * \\
(0.000)\end{array}$ & $\begin{array}{c}122.810 * * * \\
(0.000)\end{array}$ \\
\hline$Q^{2}(20)$ & $\begin{array}{c}1499.221 * * * \\
(0.000)\end{array}$ & $\begin{array}{c}1001.468 * * * \\
(0.000)\end{array}$ & $\begin{array}{c}1072.511 * * * \\
(0.000)\end{array}$ & $\begin{array}{c}1616.597 * * * \\
(0.000)\end{array}$ & $\begin{array}{c}958.452 * * * \\
(0.000)\end{array}$ & $\begin{array}{c}1134.196 * * * \\
(0.000)\end{array}$ & $\begin{array}{c}891.538 * * * \\
(0.000)\end{array}$ & $\begin{array}{c}1947.233 * * * \\
(0.000)\end{array}$ & $\begin{array}{c}924.357 * * * \\
(0.000)\end{array}$ & $\begin{array}{c}1665.034 * * * \\
(0.000)\end{array}$ \\
\hline & \multicolumn{10}{|c|}{ Unconditional Correlation } \\
\hline & consdisc & energy & finance & fmcg & health & industry & infotech & materials & telecom & utilities \\
\hline consdisc & 1.000 & 0.736 & 0.825 & 0.609 & 0.680 & 0.884 & 0.492 & 0.860 & 0.627 & 0.811 \\
\hline energy & 0.736 & 1.000 & 0.733 & 0.521 & 0.569 & 0.749 & 0.474 & 0.751 & 0.594 & 0.749 \\
\hline finance & 0.825 & 0.733 & 1.000 & 0.569 & 0.601 & 0.849 & 0.499 & 0.791 & 0.613 & 0.773 \\
\hline fmcg & 0.609 & 0.521 & 0.569 & 1.000 & 0.544 & 0.567 & 0.406 & 0.580 & 0.448 & 0.553 \\
\hline health & 0.680 & 0.569 & 0.601 & 0.544 & 1.000 & 0.653 & 0.452 & 0.653 & 0.488 & 0.614 \\
\hline industry & 0.884 & 0.749 & 0.849 & 0.567 & 0.653 & 1.000 & 0.499 & 0.860 & 0.632 & 0.822 \\
\hline infotech & 0.492 & 0.474 & 0.499 & 0.406 & 0.452 & 0.499 & 1.000 & 0.502 & 0.406 & 0.450 \\
\hline materials & 0.860 & 0.751 & 0.791 & 0.580 & 0.653 & 0.860 & 0.502 & 1.000 & 0.618 & 0.803 \\
\hline telecom & 0.627 & 0.594 & 0.613 & 0.448 & 0.488 & 0.632 & 0.406 & 0.618 & 1.000 & 0.600 \\
\hline utilities & 0.811 & 0.749 & 0.773 & 0.553 & 0.614 & 0.822 & 0.450 & 0.803 & 0.600 & 1.000 \\
\hline
\end{tabular}

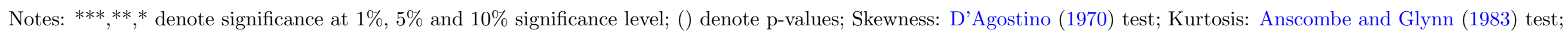
JB: Jarque and Bera (1980) normality test; ERS: Elliott et al. (1996) unit-root test; $Q(20)$ and $Q^{2}(20)$ : Fisher and Gallagher (2012) weighted Portmanteau test. 
Table 2: Averaged Connectedness Table

\begin{tabular}{|c|c|c|c|c|c|c|c|c|c|c|c|}
\hline & consdisc & energy & finance & fmcg & health & industry & infotech & materials & telecom & utilities & FROM \\
\hline consdisc & 18.3 & 8.6 & 12.3 & 6.0 & 7.4 & 13.6 & 3.6 & 12.9 & 6.1 & 11.1 & 81.7 \\
\hline energy & 10.8 & 23.9 & 10.7 & 5.1 & 6.3 & 11.4 & 3.7 & 11.0 & 6.0 & 11.0 & 76.1 \\
\hline finance & 13.0 & 9.1 & 19.8 & 5.8 & 6.6 & 13.5 & 3.8 & 11.8 & 5.8 & 10.7 & 80.2 \\
\hline fmcg & 10.0 & 6.7 & 8.9 & 33.0 & 7.1 & 8.6 & 4.0 & 8.7 & 5.2 & 7.7 & 67.0 \\
\hline health & 10.8 & 7.1 & 8.8 & 6.2 & 28.7 & 10.1 & 4.5 & 9.8 & 5.0 & 8.9 & 71.3 \\
\hline industry & 13.5 & 9.0 & 12.7 & 5.3 & 7.0 & 18.2 & 3.7 & 13.0 & 5.9 & 11.7 & 81.8 \\
\hline infotech & 6.9 & 5.5 & 6.4 & 4.7 & 6.3 & 7.0 & 46.8 & 6.9 & 4.1 & 5.5 & 53.2 \\
\hline materials & 13.3 & 9.1 & 11.5 & 5.5 & 7.1 & 13.5 & 3.8 & 18.9 & 5.8 & 11.6 & 81.1 \\
\hline telecom & 9.8 & 7.8 & 8.7 & 5.0 & 5.7 & 9.7 & 3.4 & 9.1 & 32.1 & 8.6 & 67.9 \\
\hline utilities & 12.2 & 9.6 & 11.2 & 5.2 & 7.0 & 13.0 & 3.3 & 12.4 & 5.8 & 20.4 & 79.6 \\
\hline Contribution TO others & 100.3 & 72.5 & 91.2 & 48.8 & 60.7 & 100.3 & 33.9 & 95.6 & 49.6 & 86.7 & 739.7 \\
\hline NET directional connectedness & 18.6 & -3.6 & 11.0 & -18.2 & -10.6 & 18.6 & -19.3 & 14.5 & -18.3 & 7.1 & TCI \\
\hline NPDC transmitter & 8 & 4 & 6 & 1 & 3 & 9 & 0 & 7 & 2 & 5 & 74.0 \\
\hline
\end{tabular}

Notes: Values reported are variance decompositions based on a 20-step-ahead forecasts. TVP-VAR with a lag length of order 1 is selected according to the BIC. 
Figure 1: Stock Market Returns
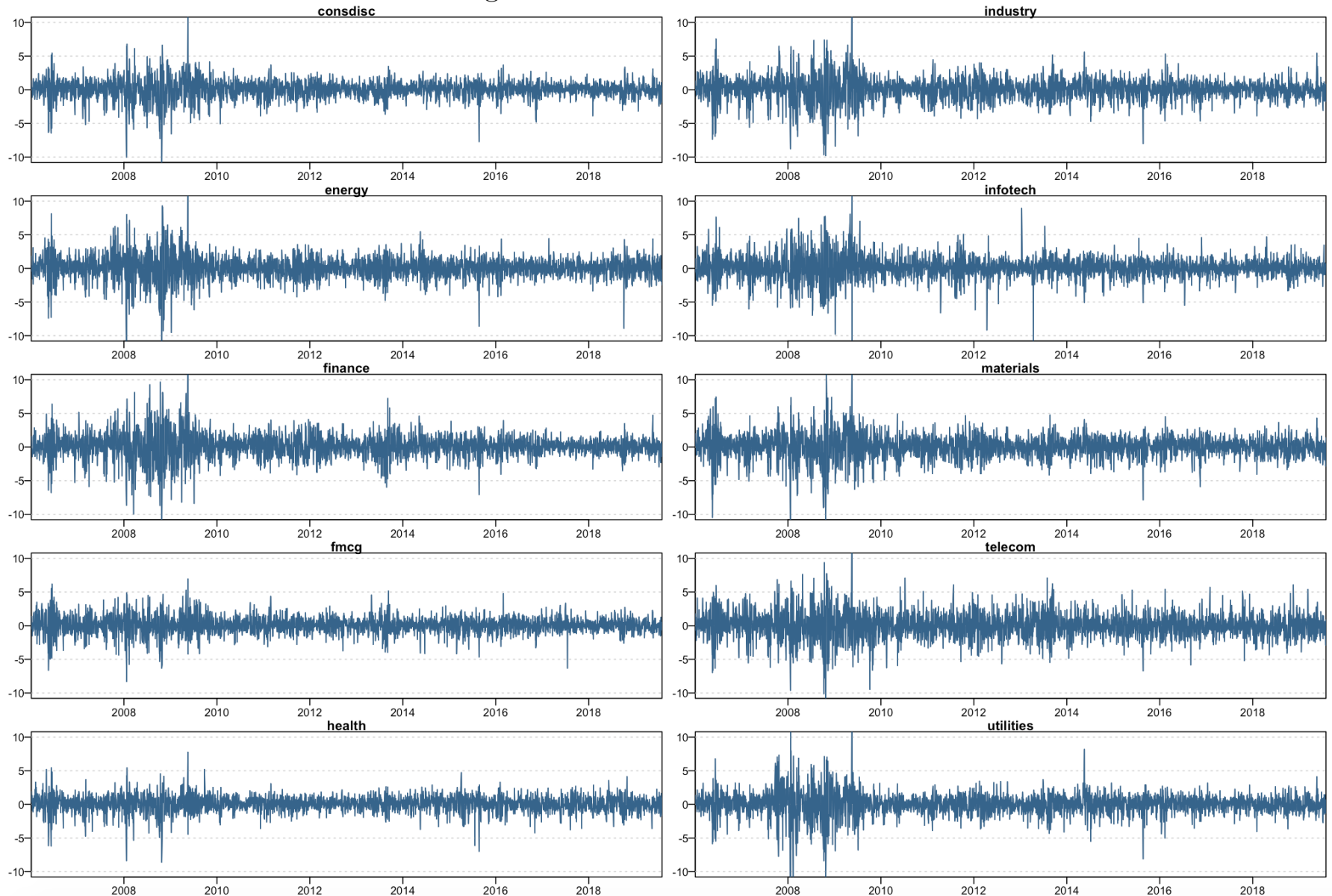

Figure 2: Dynamic Total Connectedness

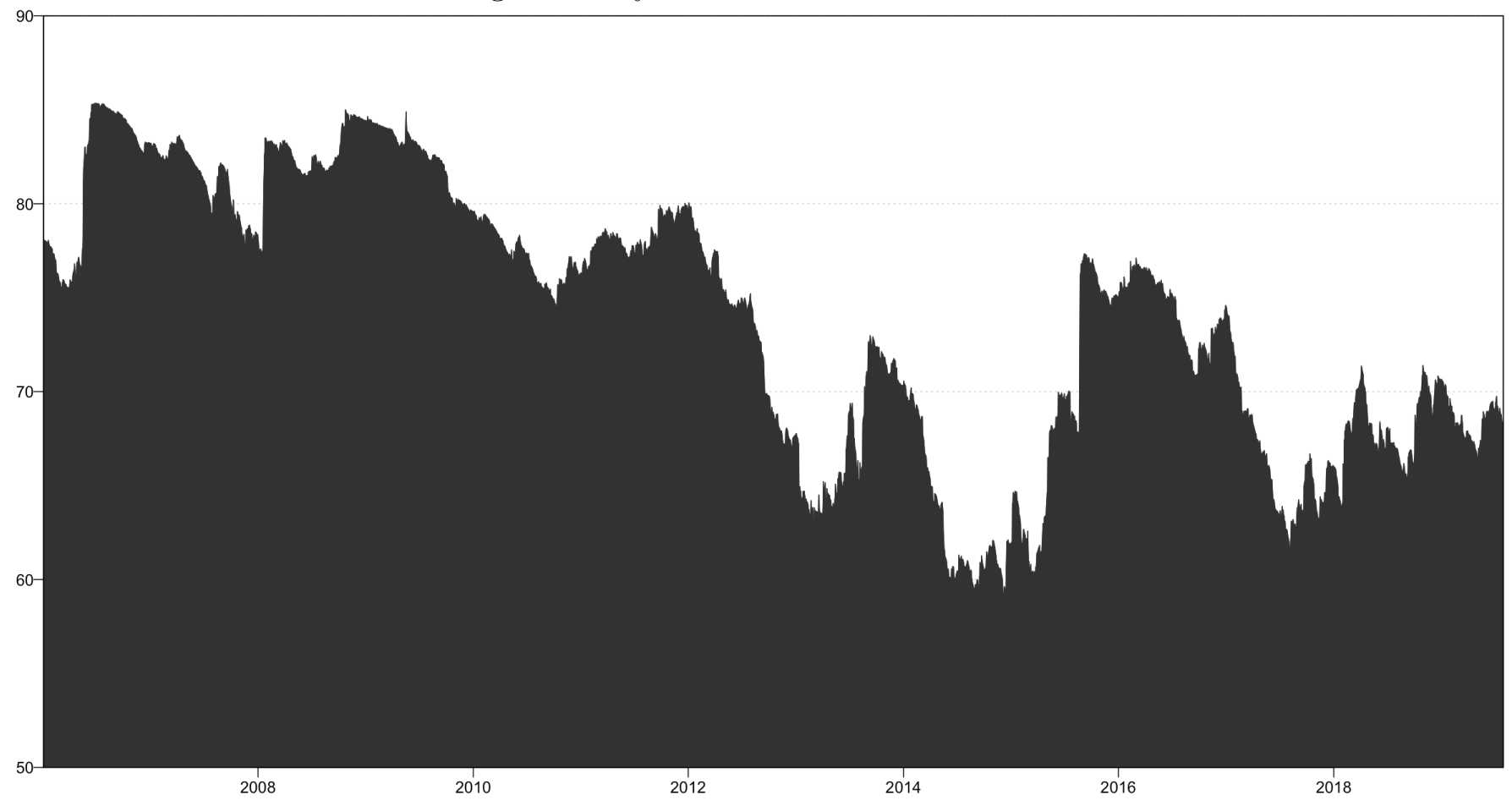


Figure 3: TO/FROM Total Directional Connectedness
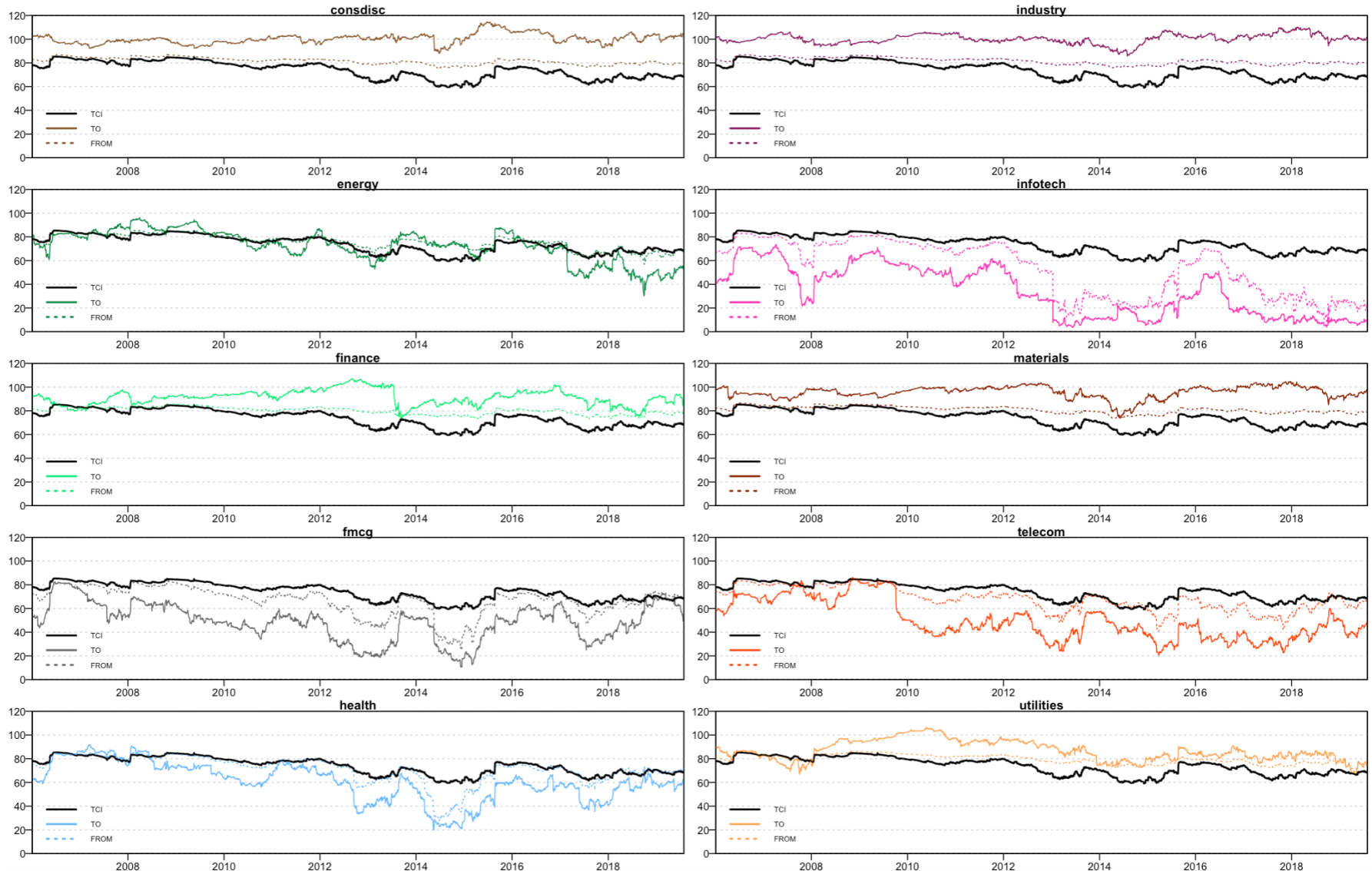

Figure 4: Net Total Directional Connectedness
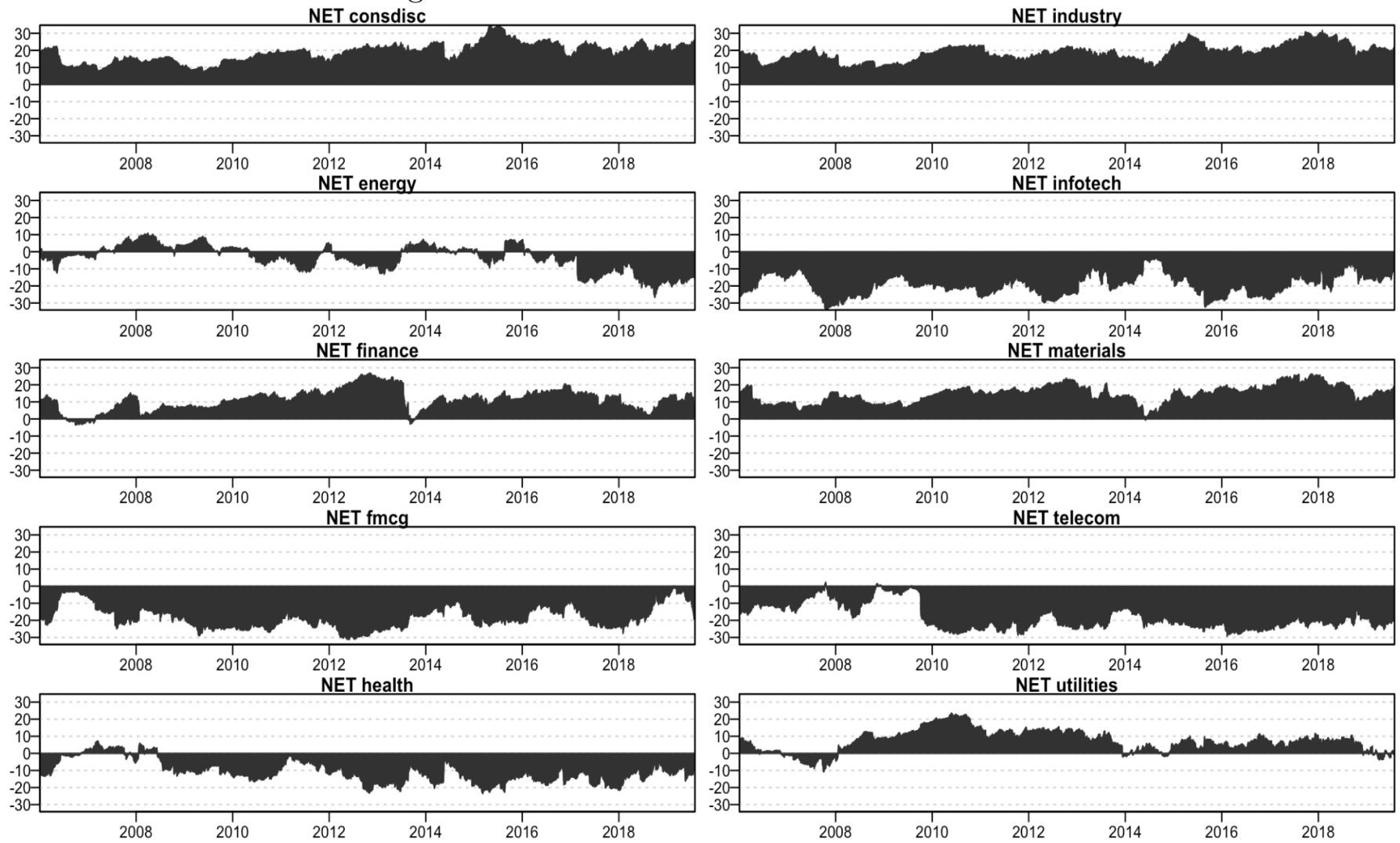
Figure 5: Net Pairwise Directional Connectedness Measures (I)
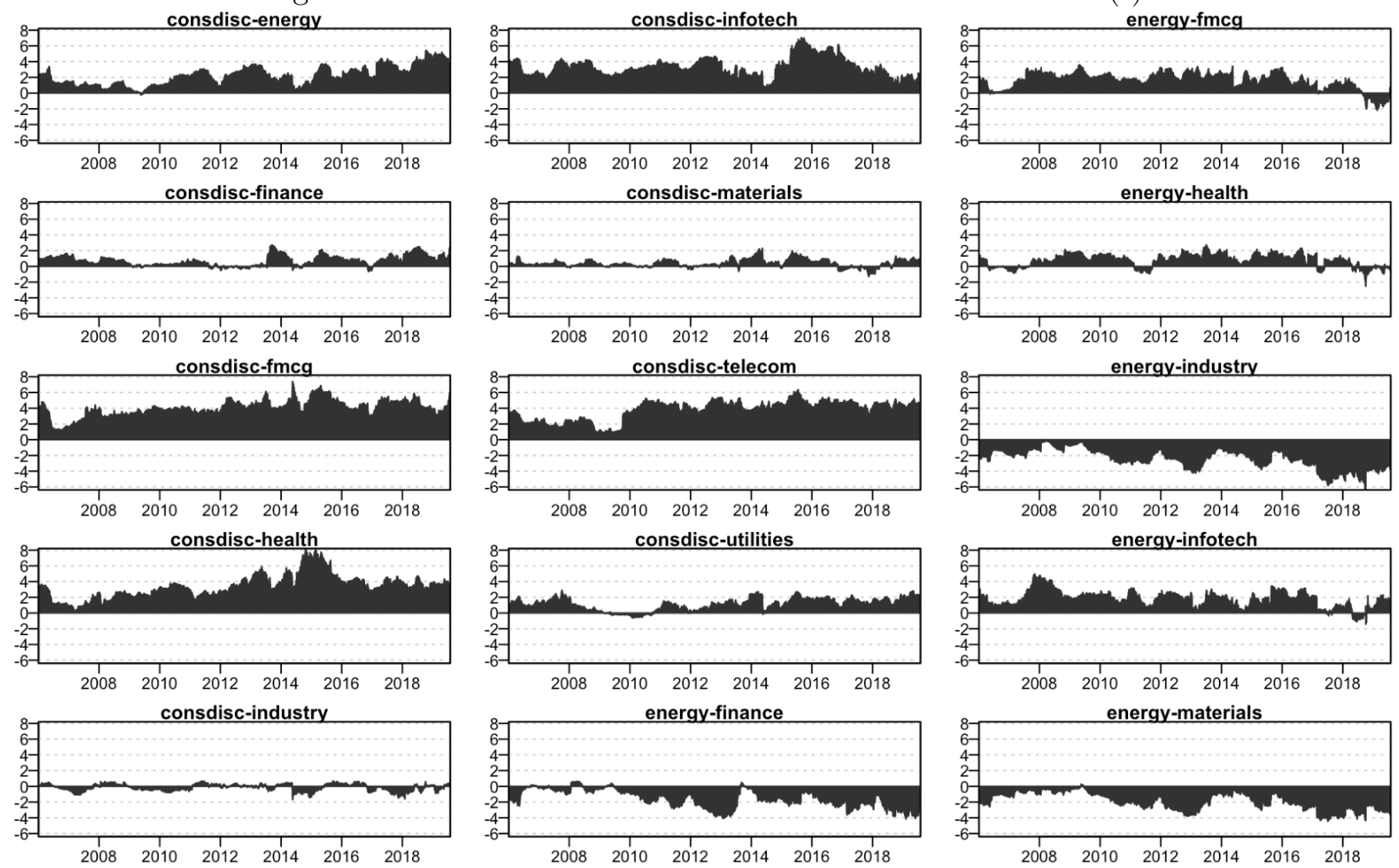

Figure 6: Net Pairwise Directional Connectedness Measures (II)
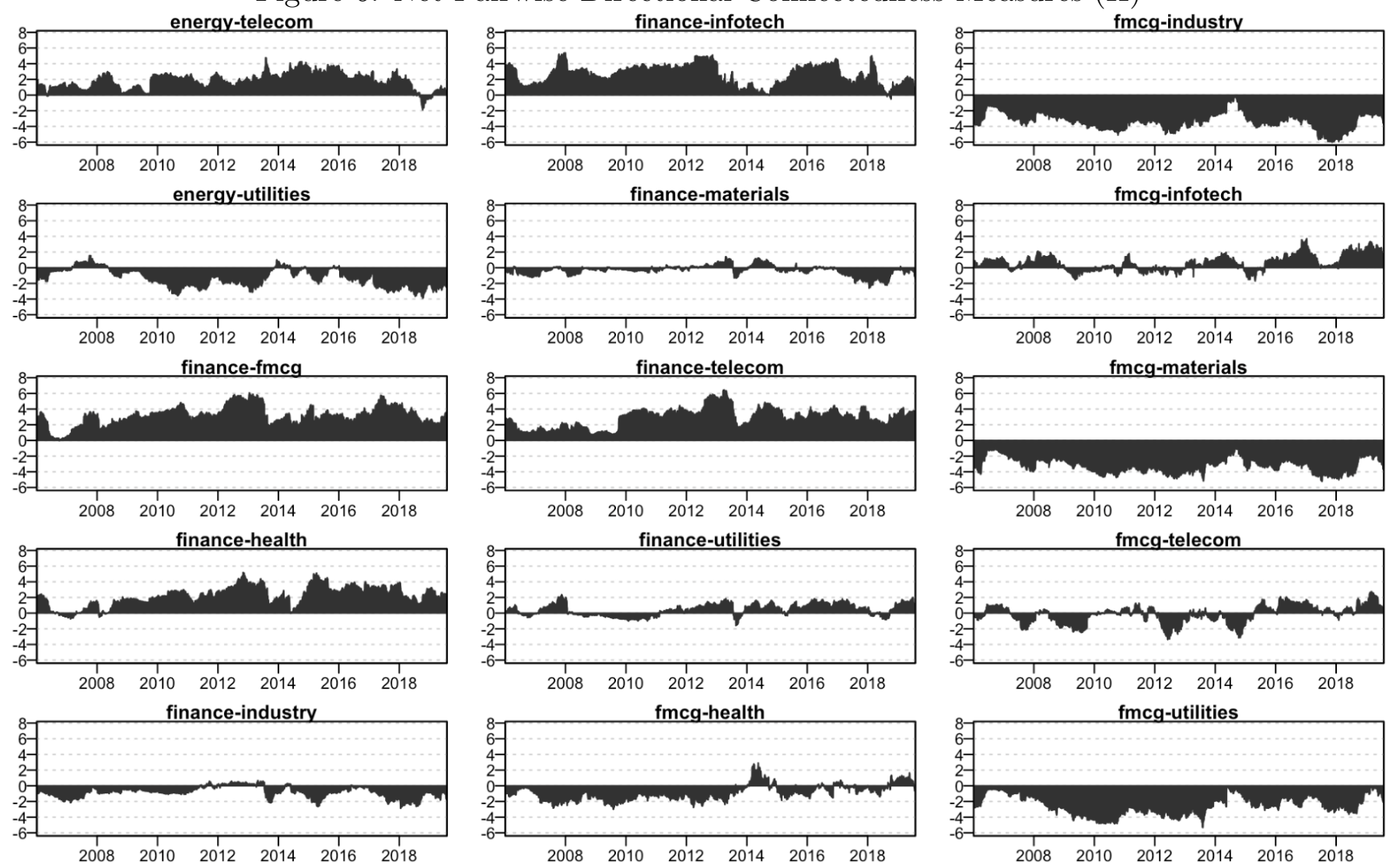
Figure 7: Net Pairwise Directional Connectedness Measures (III) health-industry
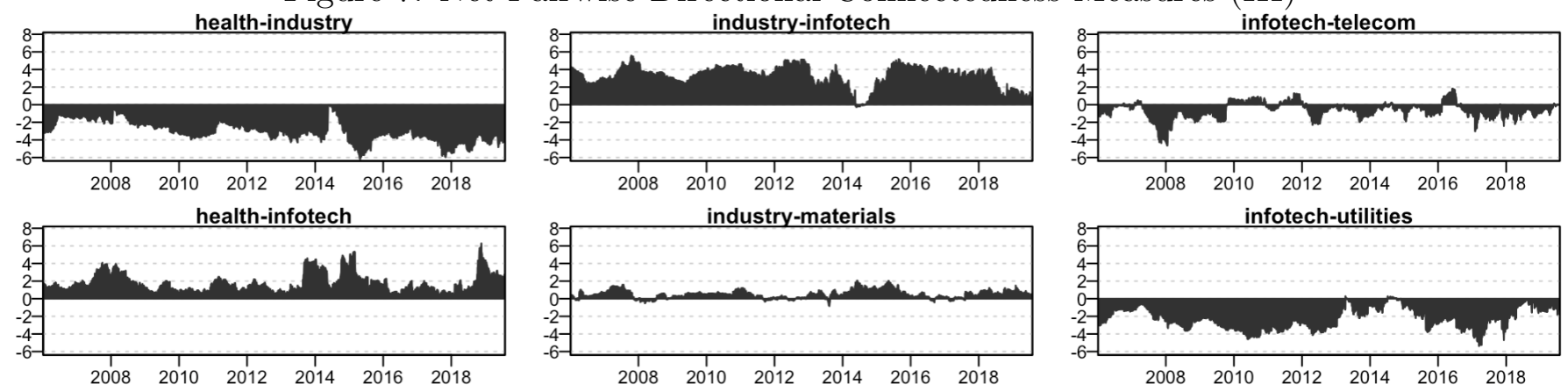

health-materials

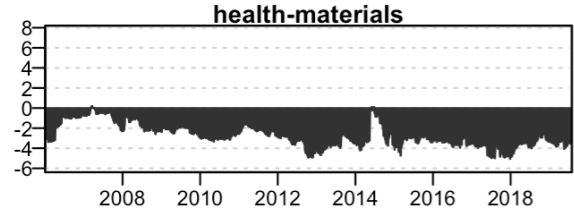
industry-telecom

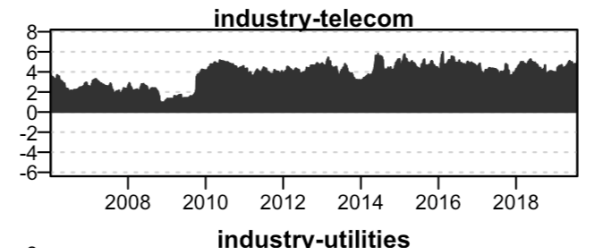
materials-telecom
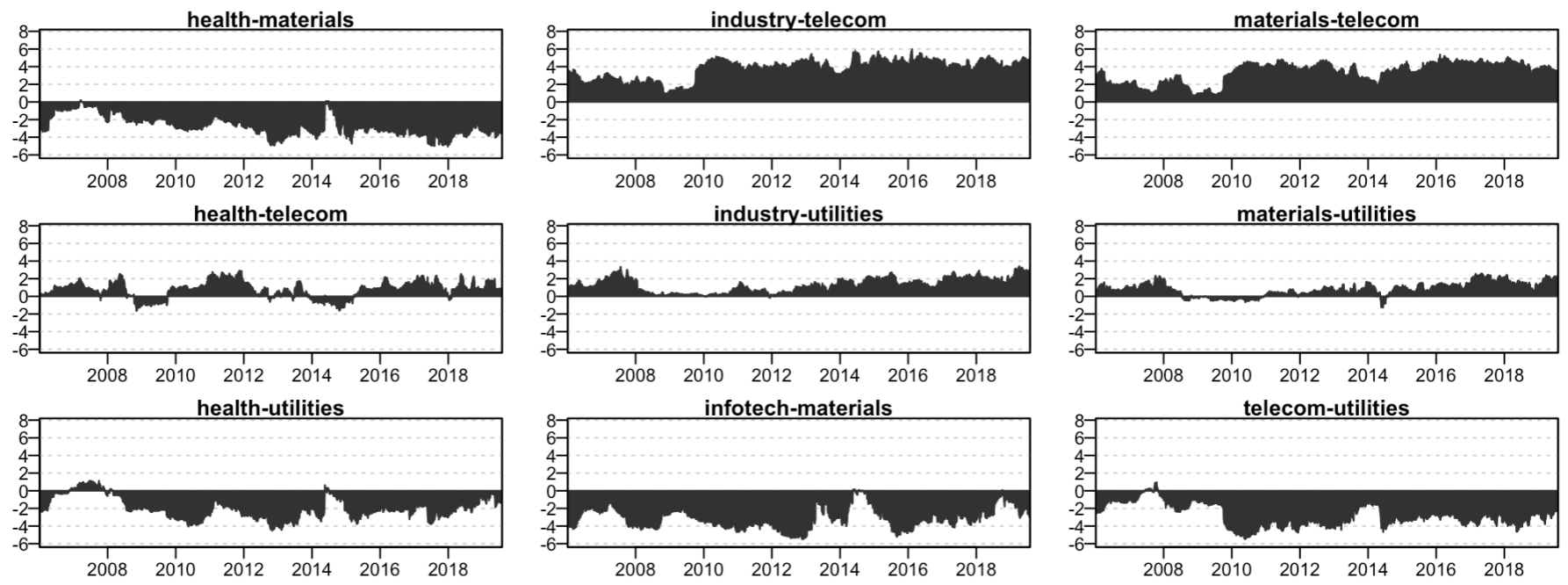